\title{
PEMBERDAYAAN EKONOMI PASIEN THALASSEMIA MELALUI KEGIATAN BISNIS ONLINE DI BANYUMAS
}

\section{Lantip Rujito *}

Universitas Jenderal Soedirman

Diyah Woro Dwi Lestari

Universitas Jenderal Soedirman

Qodri Santosa

Universitas Jenderal Soedirman

\section{Ariadne Tiara Hapsari}

Universitas Jenderal Soedirman

\begin{abstract}
ECONOMIC EMPOWERING OF THALASSEMIA PATIENTS THROUGH ONLINE ENTREPREUNERS ACTIVITIES IN BANYUMAS. Thalassemia in Banyumas is a part of portrait of Indonesia's problems. Todays, there is not yet any national thalassemia countermeasures program so that thalassemia prevalence is getting increased year by year. Increasing life expectancy of thalassemia patients brings economical problem consequence. Social stigma and businessmen support Thalassemia patients to be powered economically in their productive age. Entrepreneurship autonomy becomes an alternative to overcome it. Online entrepreneurs has flexibility, creative space, global range and unlimited time that support it to be an optional solution for preparing thalassemia patients welcoming productive age.
\end{abstract}

KEYWORDS: Alternative Entrepreneurs, Economic Empowering, Online Entrepreneurs, Thalassemia.

* Corresponding Author: Fakultas Kedokteran Universitas Jenderal Soedirman Purwokerto; Jl. HR Boenyamin 708, Grendeng, Purwokerto Utara, Kabupaten Banyumas, Jawa Tengah 53122; Email: 1.rujito@unsoed.ac.id

Article History: Received: 20-8-2017; Revised: 09-11-2017; Accepted: 01-12-2017

Permalink: http://ppm.ejournal.id/index.php/pengabdian/article/view/20

How to cite (APA): Rujito, L., Lestari, D. W. D., Santosa, Q., \& Hapsari, A. T. (2017). Pemberdayaan ekonomi pasien thalassemia melalui kegiatan bisnis online di Banyumas. Jurnal Pengabdian Pada Masyarakat, 2(2), 75-82.

This is an open access article distributed under the terms of the Creative Commons Attribution 4.0 International License, which permits unrestricted use, distribution, and reproduction in any medium, provided the original work is properly cited. @ 2017, Lantip Rujito, Diyah Woro Dwi Lestari, Qodri Santosa, Ariadne Tiara Hapsari.

\section{PENDAHULUAN}

Thalassemia di Banyumas merupakan bagian dari potret permasalahan thalasssemia di Indonesia. Persoalan thalassemia saat ini belum ada program penanggulangan thalassemia secara nasional, sehingga masih menjadi bagian masalah kesehatan umum dan tanggungjawab pemerintah daerah masing-masing. Melihat angka epidemiologi, tentu ini menjadi masalah mengingat angka pasien thalassemia meningkat dari tahun ke tahun. Peningkatan terjadi karena dengan angka pembawa sifat 3-10\% di Indonesia dan $8 \%$ di Banyumas (Hapsari \& Rujito, 2015), diperkirakan setiap tahun lahir 2500 anak dengan kondisi thalassemia. Catatan di Banyumas sendiri, dalam kurun tujuh tahun, sejak tahun 2009 (saat berdiri Yayasan Thalasssemia Indonesia Cabang Banyumas), dari 65 
pasien menjadi \pm 350 pasien pada tahun 2016 (Yayasan Thalassaemia Indonesia Cabang Banyumas, 2016).

Thalassemia sebagai penyakit hemolitik anemia masih belum dapat diterapi secara definitif. Terapi stem sel atau cangkok sumsum tulang saat ini angka keberhasilannya masih berada disekitar $33 \%$ dengan paramater yang sangat ketat. Terapi saat ini adalah terapi suportif dengan memberikan dukungan darah berupa transfusi secara rutin sejak tahun pertama diagnosis sampai akhir kehidupan. Transufsi rutin bagi pasien thalassemia dan juga obat kelasi besi untuk mengurangi deposit besi akibat pelaksaanaan transfusi rutin saat ini sudah tercover oleh layanan Badan Penyelenggara Jaminan Kesehatan (BPJS). Secara umum, minimum cost baik yang digunakan langsung terkait dengan penyakitnya, maupun biaya tidak langung operasionalnya kurang lebih memakan biaya 10 juta perbulan perpasien. Besarnya anggaran untuk pasien thalassemia dan meningkatnya pasien thalassemia ini seharusnya dapat dijadikan landasan untuk menerbitkan regulasi pencegahan di tingkat nasional sebagaimana negara-negara endemik lainnya yang terlebih dahulu menerapkan program nasionalnya seperti Cyprus, Italia, Iran, dan lain sebagainya (Rujito et al, 2015).

Sejalan dengan pemberian terapi suportif tersebut, angka kematian muda pada pasien thalasssemia di turun drastis. Kehidupan pasien thalassemia dapat bertahan lebih dari usia 15 tahun, jauh meningkat tidak seperti tahun-tahun sebelumnya yang umumnya meninggal dunia pada usia belasan tahun. Kemajuan ini patut disyukuri, namun keadaan ini memunculkan permasalahan baru terkait pengelolaan pasien thalassemia di masa mendatang.

Imbas lain dari terapi suportif adalah peningkatan angka harapan hidup dari pasien-pasien thalasssemia. Usia harapan hidup yang meningkat ini menjadi tantangan sendiri bagi keluarga maupun diri pasien thalasssemia. Kekurangpahaman masyarakat tentang penyakit thalasssemia masih menjadikan pasien thalassemia sebagai bahan olokan ataupun perlakuan yang terlalu overprotektif. Usia reproduksi menjadi masalah tersendiri mengingat mereka terkendala dengan persepsi masyarakat tentang keturunan thalassemia. Perlu adanya upaya yang dua arah baik kepada pasien thalassemianya sendiri maupun masyarakat awam tentang kesiapan mereka bereproduksi dan merencanakan pernikahan (Retissu et al, 2010). Hal lain yang menjadi kendala adalah kesiapan dunia kerja yang masih memandang rendah atau overprotektif bagi pasien thalassemia. 


\section{Permasalahan Mitra}

Beberapa pasien yang meninjak dewasa mengalami kendala mendapatkan pemasukan sebagai kesiapan mereka menghadapi masa depannya. Perlu adanya terobosan dalam hal kemandirian pasien thalassemia yang menginjak usia dewasa. Untuk itu, permasalahan mitra dapat difokuskan kepada hal-hal berikut.

Pertama, Yayasan Thalassemia Indonesia (YTI) dan Perhimpunan Orang Tua Thalassemia (POPTI) Banyumas sebagai wadah perkumpulan pegiat thalassemia masih memiliki kendala kenaikan jumlah pasien thalassemia. Sebagian berasal dari keluarga yang telah mendapatkan anak dengan thalassemia, sehingga dapat disimpulkan bahwa kesadaran akan bahaya penyakit thalassemia di kalangan keluarga thalassemia masih rendah. Angka partisipasi aktif keluarga guna deteksi dini pembawa sifat masih rendah, hal ini berdampak pada peningkatan risiko keluarga yang lain dan keturunannya memiliki anak dengan kelainan thalassemia.

Kedua, Perkumpulan Pasien Thalassemia Indoneisa (PPTI) sebagai wadah perhimpunan pasien menghadapi permasalahan terkait usia yang menginjak dewasa. Permasalahan terkait dengan perencanaan reproduksi dan pernikahan, serta dukungan lapangan kerja yang masih belum bersahabat. Masalah ini menimbulkan beban pasien thalassemia seperti takut untuk menikah, bingung menentukan pasangan dan bersikap terhadap lembaga pernikahan. Kesempatan kerja yang terbatas akibat belum siapnya masyarakat dan pihak perusahaan, membuat pasien thalassemia memiliki dilema untuk bekerja di perusahaan atau pegawai kantoran.

\section{METODE PELAKSANAAN}

Permasalahan mitra di atas merupakan masalah yang harus dicarikan solusi secara bersama-sama. Pada program pengabdian pada masyarakat berbasis riset kali ini, tim bersama mitra POPTI dan PPTI akan mencoba mengurai masalah tersebut dengan beberapa solusi yang bersifat mandiri.

Pertama, untuk masalah minimnya pengetahuan tentang thalassemia dan perlunya role model yang dapat dijadikan panutan, maka tim bersama yayasan akan membentuk divisi konseling genetik. Adanya konselor genetik di kalangan keluarga pasien akan membentuk paradigma self learning, pengetahuan dan sikap dapat langsung dicontoh dan dipraktikan oleh komunitas mereka sendiri. Divisi konseling akan mengkader anggota keluarga thalassemia yang mumpuni dan mampu menjadi duta untuk memaksimalkan program pencegahan thalasemia dari kalangan umum, dan secara khusus dari keluarga thalassemia. Detail program 
adalah 5-10 orang anggota keluarga yang mewakili wilayah penyebaran thalassemia akan dibimbing oleh ahli konseling genetik thalassemia untuk mendapatkan pelatihan, berupa pengetahuan dan keterampilan terkait konseling genetik thalassemia. Luaran program berupa adanya konselor independen tersebut diharapkan mampu berperan aktif dan menjadi fokus atau tempat untuk menemukan solusi tentang permasalahan thalassemia di daerah cakupan wilayah mereka. Konselor juga diharapkan berpartisipasi aktif dalam usaha peningkatan deteksi dini pembawa sifat dari keluarga thalassemia. Kemampuan pengetahuan dan kemampuan keterampilan deteksi diharapkan menjadi solusi dalam usaha pencegahan thalassemia dari partisipasi masyarakat thalassemia. Pada akhirnya hasilnya (outcome) adalah penurunan angka kejadian thalassemia dari kalangan keluarga thalassemia.

Kedua, permasalahan pasien dewasa muda PPTI sangat penting untuk dicarikan solusi mengingat usia produktif dan usia reproduksi bagi mereka memiliki chalenge tersendiri. Permasalahan usia reproduksi terkait kesiapan usia pernikahan akan disikapi dengan mengelola perkumpulan BATAMAS (Sahabat Thalassemia Banyumas) yang terbentuk pada akhir tahun 2016. Bersama sahabat thalassemia yang beranggotakan pasien thalassemia dan non thalassemia, tim akan memberikan pendampingan psikologi dan motivasi tentang pemecahan masalah (problem solving). Peer group discussion dengan pasien thalasssemia yang telah menikah dapat dijadikan teladan dan role model bagaimana mengelola perencanaan reproduksi dan pernikahan. Secara detail, program akan memfasilitasi pembentukan peer group discussion sebagai lanjutan dari program BATAMAS dan memfasilitasi penyusunan program Batamas yang berorientasi pada kebutuhan pasien thalassemia.

Untuk mewujudkan kemandirian kerja sebagai akibat belum siapnya kondisi masyarakat pengusaha maupun pemerintah akibat stigma negatif ataupun overproteksi dari keluarga, maka perlu dibentuk terobosan agar usia produktif pasien thalassemia dapat bermakna. Untuk itu program kali ini fokus pengabdian adalah membentuk kelompok usaha online bagi para pasien thalassemia. Usaha online ini dipilih karena beberapa alasan yaitu sebagai berikut; pasar (market) yang sangat luas, jenis usaha yang beragam, menyentuh semua aspek bisnis, dan tidak memerlukan waktu kerja dan tempat yang kaku (Utomo et al, 2012). Luaran dari progam kali ini adalah terbentuknya komunitas usaha online dari para pasien thalassemia di Banyumas, sehingga masalah kemandirian ekonomi masa depan mereka dapat mulai dirintis sejak dini. Selain itu diharapkan bahwa stigma penderita thalasssemia yang memberatkan ekonomi keluarga tidak akan terjadi. 
Pada sisi lain, program ini juga dimaksudkan untuk memberikan advokasi para pasien thalassemia yang memasuki usia kerja agar dapat diperlakukan sesuai porsinya, tidak over protektif maupun terabaikan. Advokasi ini akan dijalankan melalui program-program BATAMAS.

\section{HASIL DAN PEMBAHASAN}

\section{Peningkatan Partisipasi Deteksi Dini}

Deteksi dini apakah seorang individu mengandung gen penyebab thalassemia adalah salah satu tahapan penting dalam konsep pencegahan massal penyakit thalassemia di masyarakat. Pemeriksaan carrier atau pembawa sifat utamanya ditujukan pada pengembangan keluarga inti thalassemia. Jika seorang anak thalassemia sudah diketahui, maka langkah selanjutnya adalah melakukan skrining pembawa sifat atas seluruh anggota keluarga baik dari garis ayah maupun ibu.

Pada tahap ini tim telah berusaha melakukan berbagai macam sosialisasi atas pentingnya melakukan skrining diri thalassemia. Pada berbagai kesempatan tim thalassemia melakukan edukasi terhadap berbagai kalangan termasuk keluarga thalassemia, anak-anak SMA, dan mahasiswa. Untuk lebih mengintensifkan program pembentukan BATAMAS atau Sahabat Thalassemia Banyumas merupakan langkah strategis khususnya untuk menjangkau edukasi yang berkelanjutan atas anak-anak SMA di Banyumas. Bekerja sama dengan anak anak PMR di setiap SMA, Sahabat Thalassemia Banyumas memberikan pengetahuan setaraf atau selevel agar informasi yang disampaikan sesuai dengan bahasa anak remaja.

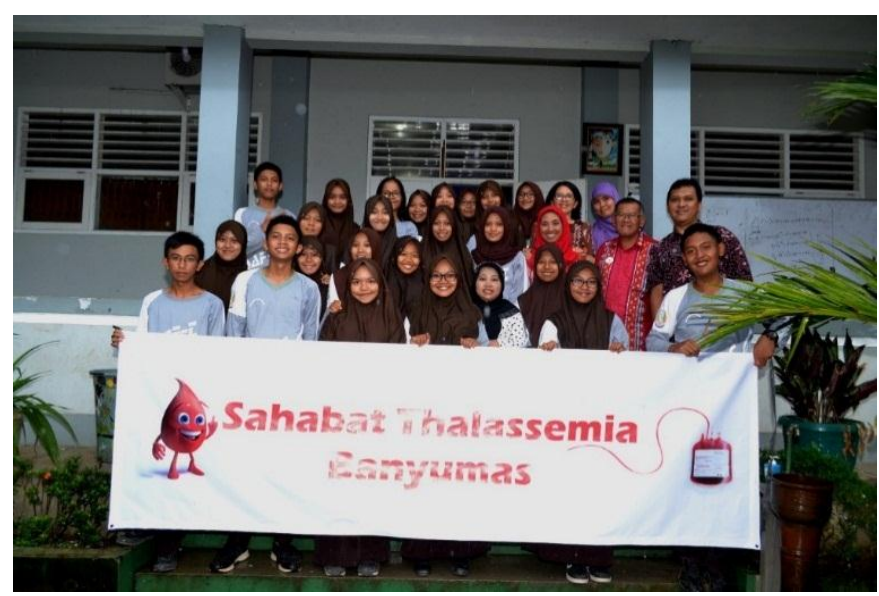

Gambar 1. Pembentukan BATAMAS (Sahabat Thalassemia Banyumas) 


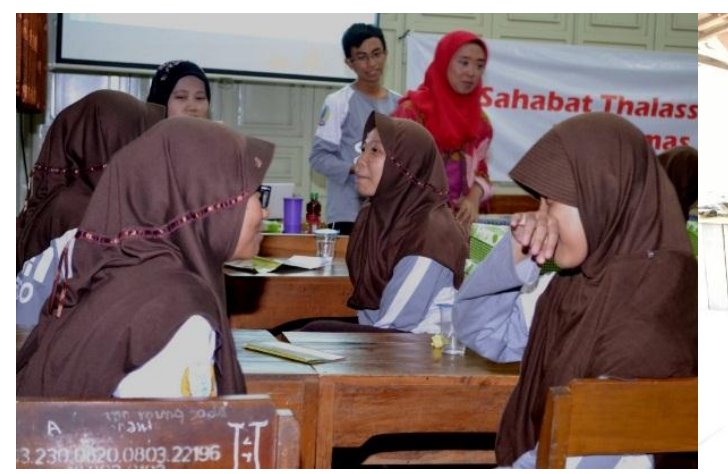

(a)

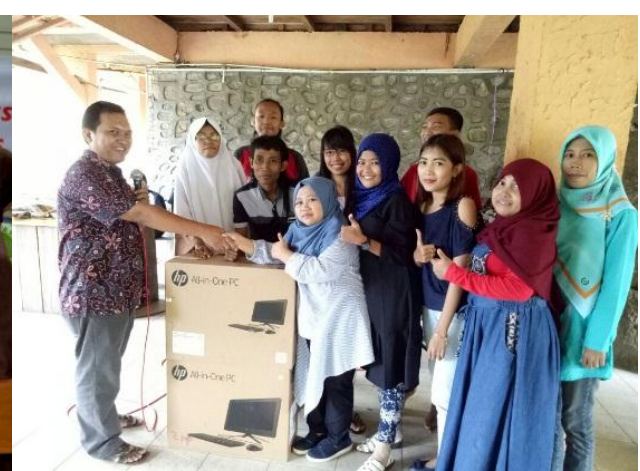

(b)

Gambar 2. Kegiatan Pemberdayaan Ekonomi Pasien Thalassemia

(a) Simulasi konseling oleh anggota BATAMAS; (b) Penyerahan perangkat elektronik untuk memulai usaha bisnis online

Pada keluarga thalassemia, pendampingan intensif sejak tahun 2010 sampai saat ini (ongoing), telah memberikan banyak perubahan atas sikap dan pengetahuan keluarga thalassemia di Banyumas. Kini pada setiap kelompok keluarga thalassemia di Banyumas telah memiliki salah satu orang yang dapat dijadikan rujukan untuk memberikan informasi thalassemia secara benar dan komprehensif. Jika ada keluarga baru pasien thalassemia yang memerlukan informasi mendetail, dapat menghubungi kelompok keluarga thalassemia di wilayah tersebut.

\section{Konsep Bisnis Online Pasien Thalassemia Banyumas}

Bisnis online adalah sesuatu aktifitas bisnis baik jasa maupun produk yang ditawarkan melalui media internet mulai dari negoisasi hingga kegiatan transaksinya, seperti menjual software, ebook dan sejenisnya tanpa harus bertatap muka dengan customer. Konsep bisnis online tidak hanya terkotak pada aktifitas jual beli saja, tetapi juga pada infrastruktur yang mendukung semua kegiatan tersebut seperti jasa internet, layanan produsen, bisnis layanan keuangan, dan berbagai pendukung lainnya (Purkon, 2015)

Karakteristik pasien thalassemia yang memasuki usia dewasa berpusat pada kekhawatiran psikologis terhadap jenis pekerjaan yang kelak yang akan dijalani. Stigma negatif pihak pengusaha terhadap pasien thalassemia berkonsekuensi terhadap mindernya para pasien thalassemia menatap dunia kerja. Hal ini seperti dialami oleh salah seorang pasien thalassemia yang dikeluarkan oleh perusahaan dalam rentang waktu 1 bulan kerja (Wirawan, 2012). 
Bisnis online yang digagas diwadahi oleh para pasien thalassemia Banyumas sendiri yang tergabung dalam perkumpulan PPTI atau Perkumpulan Pasien Thalassemia Indonesia. PPTI merupakan wadah atau organisasi tempat pasien thalassemia berbagi cerita, memberikan bantuan psikologis anggota, dan berbagai usaha untuk meningkatkan derajat kesejahteraan para anggotanya. PPTI dibentuk pada tahun 2015 dan saat ini beranggotakan kurang lebih 300-400 pasien thalassemia di Banyumas. Beberapa pasien thalassemia telah memiliki usaha riil yang membantu kemandirian mereka dan mampu mencukupi kebutuhan hidup pasien, namun masih banyak lagi pasien menginjak usia dewasa yang belum mempunyai usaha tetap. Berkembangnya bisnis internet dewasa ini mengilhami PPTI untuk mencoba memulai bisnis online untuk para anggotanya.

Rencana strategi bisnis online yang dijalankan oleh PPTI Banyumas dimulai pada tahun 2017 ini, diselenggarakan melalui beberapa tahap yaitu:

\section{Identifikasi usaha}

Kegiatan identifikasi usaha ini ditekankan mindest tentang bisnis online. PPTI akan menggali dan memutuskan untuk membangun bisnis online yang melibatkan faktor seperti: modal, produk yang akan dijual, pasar yang akan disasar, strategi pemasaran, dan kelangsungan bisnis dan tren bisnis. Saat ini PPTI Banyumas telah melakukan pertemuan yang difasilitasi oleh tim pengabdian dengan kesepakatan bahwa usaha yang akan dikerjakan adalah usaha pembayaran dan pulsa online. Selain itu juga disepakati bahwa secara bertahap usaha online akan ditingkatkan untuk mengelola jasa atau membuka toko online sendiri.

\section{Pelaksanaan}

Pelaksanaan usaha bersifat gotong royong memanfaatkan arisan anggota yang sudah rutin dilaksanakan. Saat ini usaha dijalankan oleh anggota yang memiliki akses internet dan keterjangkauan wilayah. Perangkat komputer bantuan dari pengabdian ditempatkan pada sekretariat PPTI yang juga merupakan rumah salah satu anggota yang memiliki kemudahan akses.

\section{Evaluasi}

Pada kurun waktu tertentu akan dilakukan evaluasi terkait kemajuan usaha dan juga hambatan-hambatan yang ditemui untuk selanjutnya dicarikan solusi yang cepat dan tepat.

Usaha online yang akan dijalani oleh para anggota PPTI selanjutnya dimanfaatkan untuk sebesar-besar kepentingan kegiatan PPTI di masa mendatang. 
Melalui usaha ini diharapkan kemandirian anak-anak penderita thalassemia dapat berkembang, sehingga bermanfaat untuk kehidupannya kelak.

\section{SIMPULAN}

Pelaksanaan pengabdian ini telah menghasilkan kelompok BATAMAS (Sahabat Thalassemia Banyumas) dan pusat informasi thalassemia di masingmasing kelompok keluarga thalassemia. Rintisan usaha online bagai para anakanak thalassemia dapat menjadi solusi alternatif untuk meningkatkan kemandirian anggota thalassemia di Banyumas.

\section{REFERENSI}

Hapsari, A. T., \& Rujito, L. (2015). Uji diagnostik indeks darah dan identifikasi molekuler karier talasemia $\beta$ pada pendonor darah di Banyumas. Jurnal Kedokteran Brawijaya, 28(3), 233-237.

Purkon, A. (2015). Bisnis online syariah. Jakarta: Gramedia Pustaka Utama.

Retissu, R., Sanusi, S., Muhaimin, A., \& Rujito, L. (2010). Hubungan indeks massa tubuh dengan sindroma premenstruasi. Purwokerto: Fakultas kedokteran dan ilmu-ilmu kesehatan Universitas Jenderal Soedirman.

Rujito, L., Basalamah, M., Mulatsih, S., \& Sofro, A. S. M. (2015). Molecular scanning of $\beta$-thalassemia in the southern region of Central Java, Indonesia; a step towards a local prevention program. Hemoglobin, 39(5), 330-333.

Utomo, H. T., Samopa, F., \& Setiawan, B. (2012). Pengembangan sistem pengaduan konsumen terkait bisnis online berbasis facebook open graph protocol dan sms gateway. Jurnal Teknik ITS, 1(1), A362-A367.

Wirawan, Y. (2012). Kisah hidup penderita thalassemia!. Retrieved June 17, 2017, from website: http://wirawan-yoseph.blogspot.co.Id/2012/05/kisah-hiduppenderita-thalassemia.html.

Yayasan Thalassaemia Indonesia Cabang Banyumas. (2016). Data penderita yayasan thalassaemia Banyumas. Banyumas: Buku Data Penderita Thalassaemia YTI Cabang Banyumas. 